\title{
Substratos e tempo de renovação da água residuária no crescimento do girassol ornamental em sistema semi-hidroponia
}

\author{
José A. Santos Júnior ${ }^{1}$, Hans R. Gheyi ${ }^{2}$, Nildo da S. Dias ${ }^{3}$, \\ Salomão de S. Medeiros ${ }^{4} \&$ Doroteu H. G. Filho ${ }^{5}$ \\ ${ }^{1}$ INSA. Campina Grande, PB. E-mail: eng.amiltonjr@gmail.com (Autor correspondente) \\ ${ }^{2}$ NEAS/UFRB. Cruz das Almas, BA. E-mail: hans@pq.cnpq.br \\ ${ }^{3}$ UFERSA. Mosorró, RN. E-mail: nildo@ufersa.edu.br \\ ${ }^{4}$ INSA. Campina Grande, PB. E-mail: salomao@insa.gov.br \\ ${ }^{5}$ Doutorando, UAEA/UFCG. Campina Grande, PB. E-mail: doroteufilho@hotmail.com
}

Palavras-chave: qualidade de água semiárido brasileiro floricultura

\begin{abstract}
R E S U M O
O aproveitamento do potencial hídrico e nutricional da água residuária é uma alternativa viável para incrementar a oferta de água, principalmente em regiões semiáridas. Dentro desta lógica, o objetivo deste estudo foi avaliar o comportamento do crescimento de plantas de girassol (Helianthus annuus L.) cv. Embrapa 122-V2000 para fins ornamentais, cultivadas em sistema semi-hidropônico utilizando-se diferentes substratos e água residuária em lugar da solução nutritiva. O delineamento estatístico utilizado foi o inteiramente casualizado, analisado em esquema fatorial 4 x 3, com três repetições, totalizando 36 unidades experimentais. Testaram-se quatro intervalos de tempo de renovação/substituição da água residuária (diariamente, a cada dois, três e quatro dias) e o uso de três substratos de cultivo (fibra de coco, areia e bagaço de cana de açúcar). Verificou-se que o tempo de renovação afetou negativamente o desempenho do comprimento e o diâmetro da haste, do número de folhas e área foliar; contudo, esses parâmetros de crescimento das flores se mantiveram dentro dos padrões comerciais, em todos os tempos testados.
\end{abstract}

Key words: water quality Brazilian semiarid floriculture

\section{Substrates and time intervals of renewal of wastewater on growth of ornamental sunflower in semi-hydroponic system}

\begin{abstract}
A B S T R A C T
Exploiting the potential of water and nutrients of wastewater is a viable alternative to increase the supply of water, especially in semi-arid regions. In this context, the aim of this study was to evaluate the growth of sunflower (Helianthus annuus L.), cv. Embrapa 122-V2000, for ornamental purposes, grown in semi-hydroponic system using different substrates and wastewater instead of nutrient solution. The experiment was conducted in a completely randomized design and analysed in a $4 \times 3$ factorial scheme, with three replications, totaling 36 experimental units. Four time intervals of renovation/replacement of wastewater (daily, every two, three and four days) and three substrates (coconut fiber, sand and sugar cane bagasse) for cultivation were tested. It was found that the renewal time negatively affected the performance of length and diameter of the stem, leaf number and leaf area, but these growth parameters of flowers remained within the commercial standards for all times tested.
\end{abstract}

\section{INTRODUÇÃo}

O aproveitamento da água residuária na agricultura constitui-se em um elemento estratégico na gestão integrada dos recursos hídricos, uma vez que eleva o volume da oferta e supre com eficiência as demandas do setor visto que, além do potencial hídrico, também oferece o aporte nutricional (Alves et al., 2009; Rebouças et al., 2010) amenizando o desequilíbrio do balanço nutricional existente entre áreas de produção de alimentos e as regiões de consumo de alimentos reduzindo, assim, a necessidade de importação de fertilizantes pelas regiões produtoras.

Diversos trabalhos confirmam as vantagens proporcionadas pelo aproveitamento de águas residuárias na produção agrícola
(Chatzakis et al., 2011; Santos Júnior et al., 2011; Andrade et al., 2012) no entanto, ainda são escassas informações que relacionem o aproveitamento da água residuária em cultivos hidropônicos.

Os sistemas semi-hidropônicos de circulação fechada, caracterizados por ocuparem pequenas áreas e favorecem o aumento da eficiência no uso da água e nutrientes pelas plantas, são tecnologias que possibilitam a utilização de água residuária no cultivo de culturas nobres, de alto valor e liquidez de mercado (Santos Júnior et al., 2011). Outro fator mitigador de impactos ambientais deste sistema de cultivo é a utilização de subprodutos de diversas atividades antrópicas como substrato, oferecendo um destino adequado a materiais considerados poluidores ambientais. 
Esta tecnologia de cultivo de alta eficiência do uso da água, associada à utilização de culturas rentáveis, dentro do contexto de um plano de negócios estruturado, é também uma alternativa de geração de renda para comunidades de agricultores familiares do semiárido brasileiro, região esta que abriga $15 \%$ da população brasileira (Medeiros et al., 2012) e dispõe de cerca de 3\% dos seus recursos hídricos. A floricultura, por exemplo, emprega em média de $15 \mathrm{a} 20$ pessoas por hectare e rende de 50 a 100 mil reais por ano, enquanto a fruticultura gera aproximadamente cinco empregos na mesma área e rende próximo de 20 mil reais (Neves \& Amaral, 2008). Dentre as flores tropicais cita-se o girassol cujo buquê de flores atinge preços superiores a $\mathrm{R} \$ 150,00$ e, além disto, possui adaptabilidade às diferentes condições edafoclimáticas sendo que sua produtividade é pouco influenciada pela latitude, altitude e fotoperíodo, fato que favorece seu cultivo em regiões semiáridas.

Deste modo, o presente trabalho foi desenvolvido com o objetivo de avaliar o crescimento de plantas de girassol para fins ornamentais cultivadas em sistema semi-hidropônico utilizando diferentes substratos e água residuária no lugar da solução nutritiva.

\section{Material e Métodos}

O trabalho foi conduzido entre novembro de 2011 e janeiro de 2012, em casa de vegetação da Universidade Federal de Campina Grande, município de Campina Grande, PB ( $7^{\circ} 12^{\prime}$ $52^{\prime \prime}$ latitude Sul, $35^{\circ} 54^{\prime} 24^{\prime \prime}$ longitude Oeste com altitude média de $550 \mathrm{~m}$ ).

O delineamento experimental utilizado foi o inteiramente casualizado, analisado em esquema fatorial $4 \times 3$ com três repetições totalizando 36 unidades experimentais, sendo avaliado o crescimento de plantas de girassol em sistema semi-hidropônico através de três substratos de cultivo (fibra de coco, areia e bagaço de cana-de-açúcar) e água residuária (AR) em quatro tempos de renovação/substituição. A fibra de coco utilizada foi adquirida no comércio, a areia grossa foi lavada previamente e o bagaço de cana-de- açúcar foi obtido em usina de cana-de-açúcar triturado na forrageira. A caracterização físico-química desses substratos está apresentada na Tabela 1 .

Cada parcela experimental foi composta por vasos de $6 \mathrm{~L}$, preenchidos com $0,5 \mathrm{~kg}$ de brita $+1 \mathrm{~kg}$ de substrato (em base seca), separados por tela de nylon. Os vasos foram preparados com quatro furos na base e colocados em uma bacia em que se adaptou uma mangueira de drenagem ligada a uma garrafa pet de $2 \mathrm{~L}$ para coleta do volume drenado; dado ao contato direto entre o vaso e a bacia, a percolação da água residuária (AR)

Tabela 1. Caracterização físico-química dos substratos de cultivo, EMBRAPA (1997)

\begin{tabular}{|c|c|c|c|c|c|c|}
\hline \multirow{2}{*}{ Substrato } & $\mathbf{N}$ & $\bar{P}$ & $\bar{K}$ & $\mathrm{Da}$ & $\mathrm{Dr}$ & \multirow{2}{*}{$\begin{array}{c}\mathbf{Y} \\
(\%)\end{array}$} \\
\hline & \multicolumn{3}{|c|}{$\mathrm{g} \mathrm{kg}^{-1}$} & \multicolumn{2}{|c|}{$\mathrm{kg} \mathrm{dm}^{-3}$} & \\
\hline Fibra de coco & 0,45 & 3,67 & 14,88 & 0,56 & 0,14 & 75 \\
\hline Areia & - & - & - & 1,55 & 2,65 & 42 \\
\hline Bagaço de cana de açúcar & 5,43 & 1,08 & 6,58 & 0,33 & 0,086 & 74 \\
\hline
\end{tabular}

$\mathrm{N}$ - Nitrogênio total; P - Fósforo; K - Potássio; Da - Densidade aparente; Dr - Densidade real; Y - Porosidade ocorreu lentamente, através dos pequenos espaços existentes nesta interface, favorecendo a permanência da AR dentro do vaso por mais tempo e proporcionando um tempo maior de absorção para a planta até que a drenagem finalizasse. Isto evitava que, sob a ação da gravidade, a AR escoasse rapidamente por caminhos preferenciais, sem umedecer todo o substrato, comprometendo a necessidade hídrica e nutricional das plantas.

A cultivar de girassol estudada foi a Embrapa 122-V2000 e o semeio foi feito diretamente nos vasos; utilizou-se água residuária em quatro tempos de renovação/substituição: diariamente $\left(\mathrm{M}_{1}\right)$, a cada $2\left(\mathrm{M}_{2}\right), 3\left(\mathrm{M}_{3}\right)$ e $4\left(\mathrm{M}_{4}\right)$ dias com reaplicação do percolado três vezes por dia, às 8,12 e $16 \mathrm{~h}$ em todos os tratamentos, ou seja, a água residuária era aplicada às $8 \mathrm{~h}$; às $12 \mathrm{~h}$ o volume drenado e coletado nas garrafas PET era reaplicado e às $16 \mathrm{~h}$ o volume drenado era mensurado e novamente reaplicado às plantas.

No final do tempo (dias) de circulação da água residuária (AR) específico de cada manejo, o volume lixiviado era mensurado e descartado e um novo volume inicial de $2 \mathrm{~L}$ de água residuária era aplicado ao sistema. Com o aumento do consumo hídrico médio das plantas observado aos 36 dias após a semeadura (DAS), o volume inicial utilizado passou a ser de $3 \mathrm{~L}$, visando uniformizar a disponibilidade de água entre as plantas dos diferentes tratamentos.

A água residuária utilizada no experimento foi proveniente de um riacho dentro da área experimental da UFCG; este corpo de água canaliza o esgoto doméstico do Bairro Monte Santo, imediatamente a montante do local de coleta. Para não ocorrer efeito da sazonalidade na concentração de nutrientes, todo o volume foi coletado apenas uma vez, antes do período das chuvas, no ano hidrológico de 2011. As características físico-químicas da água residuária filtrada por ocasião do bombeamento foram determinadas no Laboratório de Referência em Dessalinização, UFCG, Campina Grande, PB, e estão descritas na Tabela 2.

Aos 21, 28, 35 e 42 DAS foram mensurados os valores biométricos das plantas, a saber: comprimento da haste $(\mathrm{CH})$; diâmetro da haste (DH); número de folhas (NF) e área foliar (AF). O CH foi mensurado do colmo da planta, rente ao substrato, até a bifurcação da última folha, entre a haste e/ou

Tabela 2. Caracterização físico-química da água residuária filtrada utilizada

\begin{tabular}{lcc}
\hline \multicolumn{1}{c}{ Parâmetros } & Unidade & Resultado \\
$\mathrm{CE}$ & $\left(\mathrm{dS} \mathrm{m}^{-1}\right) \mathrm{a} 25^{\circ} \mathrm{C}$ & 1,44 \\
$\mathrm{pH}$ & - & 7,2 \\
Dureza em Ca & $\left(\mathrm{mg} \mathrm{L}^{-1}\right)$ & 47,8 \\
Dureza em $\mathrm{Mg}^{++}$ & $\left(\mathrm{mg} \mathrm{L}^{-1}\right)$ & 28,3 \\
Dureza total $\left(\mathrm{CaCO}_{3}\right)$ & $\left(\mathrm{mg} \mathrm{L}^{-1}\right)$ & 237,5 \\
$\mathrm{Na}^{+}$ & $\left(\mathrm{mg} \mathrm{L}^{-1}\right)$ & 186,0 \\
$\mathrm{~K}^{+}$ & $\left(\mathrm{mg} \mathrm{L}^{-1}\right)$ & 31,1 \\
Ferro total & $\left(\mathrm{mg} \mathrm{L}^{-1}\right)$ & 0,18 \\
Alcalinidade em bicarbonatos, $\left(\mathrm{CaCO}_{3}\right)$ & $\left(\mathrm{mg} \mathrm{L}^{-1}\right)$ & 367,6 \\
$\mathrm{SO}_{4}^{--}$ & $\left(\mathrm{mg} \mathrm{L}^{-1}\right)$ & 40,4 \\
Fósforo total & $\left(\mathrm{mg} \mathrm{L}^{-1}\right)$ & 9,0 \\
$\mathrm{Cl}^{-}$ & $\left(\mathrm{mg} \mathrm{L}^{-1}\right)$ & 305,3 \\
$\mathrm{~N}^{-} \mathrm{NO}_{3}{ }^{-}$ & $\left(\mathrm{mg} \mathrm{L}^{-1}\right)$ & 0,04 \\
$\mathrm{~N}^{-\mathrm{NH}_{3}}$ & $\left(\mathrm{mg} \mathrm{L}^{-1}\right)$ & 49,9 \\
$\mathrm{SiO}_{2}$ & $\left(\mathrm{mg} \mathrm{L}^{-1}\right)$ & 20,0 \\
\hline
\end{tabular}


capítulo; o DH foi mensurado sempre no mesmo local, na altura de $0,03 \mathrm{~m}$ da base do colo da planta; no NF foram contabilizadas aquelas cujo tamanho da nervura central era superior a 0,03 $\mathrm{m}$, sendo também sadias e fotossinteticamente ativas. A AF foi calculada utilizando-se o método proposto por Maldaner et al. (2009), a saber: $\mathrm{AF}=0,1328 \mathrm{C}^{2,5569}$, em que C é o comprimento da nervura central da folha $(\mathrm{cm})$.

Os resultados do experimento foram submetidos à análise de variância comparando-se, por meio de análise de regressão, os tempos de renovação/substituição da água residuária (fator quantitativo) e através do teste de médias (Tukey) os diferentes substratos de cultivo (fator qualitativo) a nível de 0,05 de probabilidade, utilizando-se software estatístico SISVAR versão 5.2 (Ferreira, 2008). Os dados das variáveis comprimento e diâmetro do caule, número de folhas e área foliar, foram transformados mediante a equação $(\mathrm{X}+0,5)^{0,5}$.

\section{Resultados e Discussão}

O tempo de renovação da água residuária $(\mathrm{AR})$ afetou negativamente todas as variáveis monitoradas $(\mathrm{CH}, \mathrm{DH}, \mathrm{NF}$ e $\mathrm{AF}$ ); contudo, o $\mathrm{CH}$ (Tabela 3) só foi afetado significativamente a partir dos 35 dias após a semeadura (DAS) enquanto nas demais variáveis analisadas se identificou efeito significativo $(p<0,01)$ em todo o período avaliado.

Aos 21 DAS não se observou diferença significativa entre o $\mathrm{CH}$ das plantas cultivadas em fibra de coco e areia, média de $37 \mathrm{~cm}$, resultado este $20 \mathrm{~cm}$ maior que o observado nas plantas cultivadas em bagaço de cana-de-açúcar; da mesma forma, aos 28 DAS, as plantas cultivadas em fibra de coco e areia produziram um $\mathrm{CH}$ médio de $62 \mathrm{~cm}$, resultado 2,8 vezes maior em relação aos valores médios de $\mathrm{CH}$ verificados nas plantas cultivadas em bagaço de cana-de-açúcar (Figura 1A).

Aos 35 DAS não se observou diferença entre os resultados de $\mathrm{CH}$ das plantas cultivadas em fibra de coco e areia; já aos 42 DAS os resultados observados nas plantas em função dos diferentes substratos diferiram significativamente entre si, sendo observadas médias de $139 \mathrm{~cm}$ nas plantas cultivadas em fibra de coco, $126 \mathrm{~cm}$ nas cultivadas em areia e $35 \mathrm{~cm}$ nas cultivadas em bagaço de cana-de-açúcar.

Quanto ao tempo de renovação, observou-se que aos $35 \mathrm{e}$ 42 DAS, o CH das plantas sob renovação da AR, a cada 4 dias, foi, respectivamente, 14 e 16\% menor em relação ao das plantas
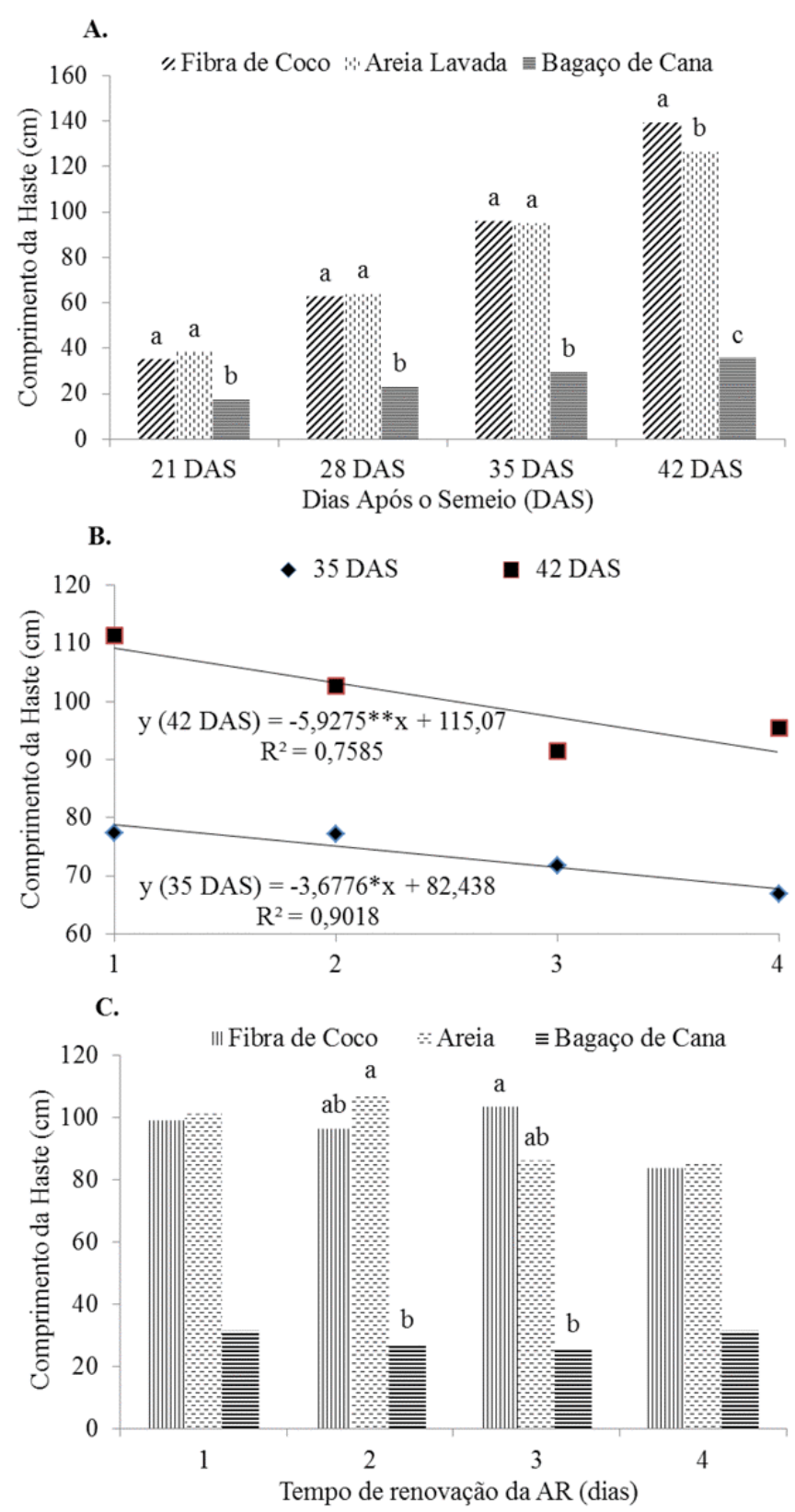

Figura 1. Comprimento da haste de plantas de girassol (cv. Embrapa 122-V2000) aos 21, 28, 35 e 42 dias em função dos substratos (A); aos 35 e 42 DAS em função do tempo de renovação/substituição da água residuária (B) e aos 35 DAS, desdobramento do fator substrato dentro do fator tempo de renovação da água residuária (C)

Tabela 3. Resumo da ANOVA para o comprimento da haste ${ }^{1}$ de plantas de girassol (cv. Embrapa 122-V2000) aos 21, 28, 35 e 42 dias após a semeadura (DAS) cultivado em diferentes substratos e tempos de renovação/substituição da água residuária

\begin{tabular}{|c|c|c|c|c|c|}
\hline \multirow{2}{*}{ Causa de variação } & \multirow{2}{*}{ GL } & \multicolumn{4}{|c|}{ Quadrado médio } \\
\hline & & 21 DAS & 28 DAS & 35 DAS & 42 DAS \\
\hline Tempo de renovação da AR (T) & 3 & $13,0195^{\text {ns }}$ & $86,5306^{\text {ns }}$ & $224,9874^{\star}$ & $694,8387^{*}$ \\
\hline Regressão linear & 1 & - & - & $608,6722^{\star \star}$ & $1581,234^{\star *}$ \\
\hline Substrato (S) & 2 & $1524,86^{\star *}$ & $6490,95^{* *}$ & $17460,29^{* *}$ & $38653,05^{\star}$ \\
\hline Interação T x S & 6 & $53,0959^{\text {ns }}$ & $73,6681^{\mathrm{ns}}$ & $196,4407^{*}$ & $291,7882^{\text {ns }}$ \\
\hline Resíduo & 24 & 28,2586 & 29,3725 & 41,118 & 125,1583 \\
\hline CV & $(\%)$ & 8,80 & 5,54 & 4,60 & 5,76 \\
\hline
\end{tabular}

\footnotetext{
*, ${ }^{\star *}$ Significativo a 0,05 e 0,01 de probabilidade, respectivamente; ns - Não significativo, pelo teste F; GL - Grau de liberdade; CV- Coeficiente de variação.

1 Valores transformados pela equação $(X+0,5)^{0,5}$
} 
sob AR renovada diariamente (Figura 1B). No entanto, convém ressaltar que apesar desta redução as plantas alcançaram $\mathrm{CH}$ compatível com os padrões comerciais para produção de flores. De acordo com Neves et al. (2009) para atender aos elevados padrões comerciais, as plantas de girassol ornamental devem apresentar $\mathrm{CH}$ entre 35 e $40 \mathrm{~cm}$, ou seja, resultados bem inferiores aos obtidos no presente trabalho aos 42 DAS, sendo que, em função desses resultados, é possível ampliar o espectro de utilização das flores através do corte da haste, de acordo com a finalidade e o tamanho desejado.

Aos 35 DAS houve efeito significativo da interação tempo de renovação vs substratos de cultivo; na análise do desdobramento do fator substrato dentro do fator renovação da AR verificase que, quando a renovação ocorre a cada 2 dias, o $\mathrm{CH}$ das plantas cultivadas em areia apresenta melhores tendências de crescimento em relação as plantas cultivadas em bagaço de cana- de-açúcar; entretanto, quando a renovação ocorre a cada três dias, as melhores tendências de $\mathrm{CH}$ são verificadas nas plantas cultivadas em fibra de coco, em relação ao $\mathrm{CH}$ das plantas cultivadas em bagaço de cana-de-açúcar (Figura 1C). O incremento do tempo de renovação da $\mathrm{AR}$ afeta negativamente mais as plantas cultivadas em areia do que em fibra de coco em função das diferentes capacidades de retenção de água de cada substrato mencionado; já o bagaço da cana-de- açúcar apresentou um grau de retenção tal que proporcionou a ocorrência de anoxia nas plantas e apodrecimento no substrato.

De acordo com os resultados da Tabela 4, os fatores tempo de renovação da AR e os substratos de cultivo influenciaram significativamente o DH das plantas em todas as épocas de avaliação.

Segundo Curti (2010) é desejável que o diâmetro da haste seja resistente para possibilitar a sustentação da inflorescência do girassol que, em geral, tem maior massa em relação às outras espécies de flor de corte, como a rosa e a gérbera, entre outras. Neste contexto notou-se que aos 21 DAS as plantas cultivadas sob renovação/substituição da AR a cada dois dias, produziram um DH 6,27\% mais espesso que as plantas sob renovação diária; verificou-se também um decréscimo de $4,81 \%$ no $\mathrm{DH}$ quando se comparam os valores das plantas cultivadas sob renovação/substituição da $\mathrm{AR}$ a cada dois dias com as plantas sob renovação/substituição da solução percolada a cada três dias; e de 16,69\% em relação às plantas irrigadas sob manejo de renovação do AR, a cada quatro dias (Figura 2A).
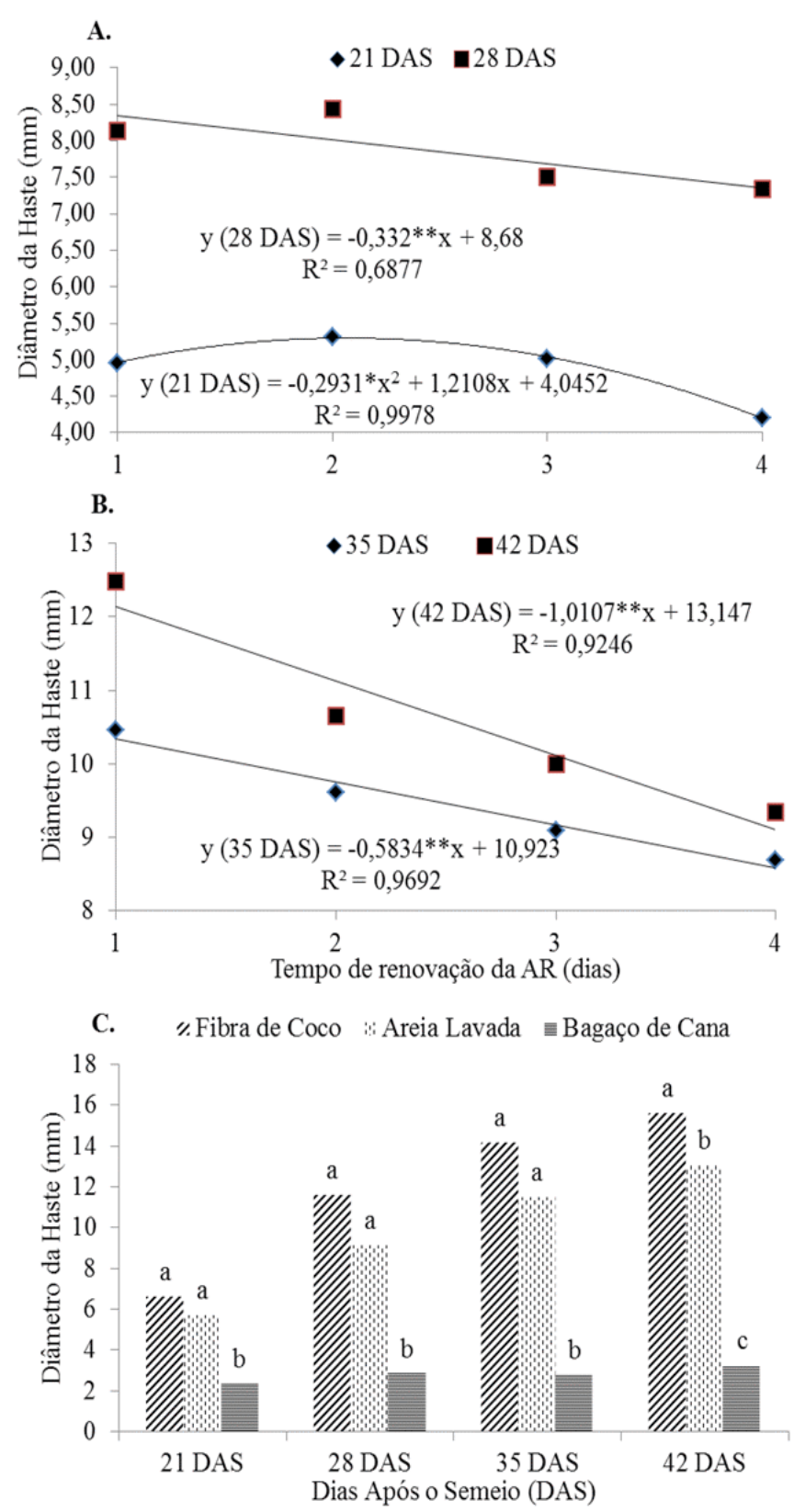

Figura 2. Diâmetro da haste de plantas de girassol (cv. Embrapa 122-V2000) aos 21, 28 (A), 35 e 42 dias após a semeadura (DAS) (B) em função dos diferentes tempos de renovação/substituição da água residuária e em diferentes substratos $(C)$

Tabela 4. Resumo da ANOVA para o diâmetro da haste' de plantas de girassol (cv. Embrapa 122-V2000) aos 21, 28, 35 e 42 dias após a semeadura (DAS), cultivadas em diferentes substratos e tempos de renovação/substituição da água residuária

\begin{tabular}{|c|c|c|c|c|c|}
\hline \multirow{2}{*}{ Causa de variação } & \multirow{2}{*}{ GL } & \multicolumn{4}{|c|}{ Quadrado médio } \\
\hline & & 21 DAS & 28 DAS & 35 DAS & 42 DAS \\
\hline Tempo de renovação da AR (T) & 3 & $2,0068^{\star \star}$ & $2,4041^{\star \star}$ & $5,2683^{\star \star}$ & $16,5709^{\star \star}$ \\
\hline Regressão linear & 1 & - & $3,9723^{\star}$ & $15,3183^{* *}$ & $45,9651^{\star \star}$ \\
\hline Regressão quadrática & 1 & $3,0917^{\star}$ & - & - & - \\
\hline Substrato (S) & 2 & $61,1394^{\star *}$ & $244,5871^{\star \star}$ & $425,651^{* *}$ & $511,4698^{\star \star}$ \\
\hline Interação T x S & 6 & $0,8418^{\text {ns }}$ & $0,6181^{\text {ns }}$ & $0,7369^{\text {ns }}$ & $1,3333^{\text {ns }}$ \\
\hline Resíduo & 24 & 0,6530 & 0,5008 & 0,6061 & 1,0234 \\
\hline CV & $(\%)$ & 7,89 & 4,08 & 4,28 & 4,71 \\
\hline
\end{tabular}

* , ${ }^{\star \star}$ Significativo a 0,05 e 0,01 de probabilidade, respectivamente; ns - Não significativo, pelo teste F; GL - Grau de liberdade; CV- Coeficiente de variação.

${ }^{1}$ Valores transformados pela equação $(X+0,5)^{0,5}$ 
Ainda aos 21 DAS, quanto ao fator substrato, as plantas cultivadas aos 21 DAS em fibra de coco produziram hastes cerca de $4 \mathrm{~mm}$ mais espessas que as cultivadas em bagaço de cana-de-açúcar (Figura 2C).

Aos 28 DAS observou-se efeito linear decrescente no DH em função da renovação da $\mathrm{AR}$, sendo estimada, com base na equação de regressão, uma redução de $4 \%$ por incremento unitário do tempo de renovação da AR. Notou-se ainda uma diferença de $12 \%$ na espessura média da haste das plantas sob renovação diária da $\mathrm{AR}$ em relação às sob renovação a cada quatro dias (Figura 2A). Ainda aos 28 DAS constatou-se que as plantas cultivadas em fibra de coco e areia obtiveram hastes aproximadamente quatro vezes mais espessas que as plantas cultivadas em bagaço de cana-de-açúcar (Figura 2C).

Aos 35 DAS observou-se um decréscimo de 5,3\% no DH das plantas por incremento unitário do tempo de renovação/ substituição da AR, com disparidade de 16,93\% entre a espessura da haste das plantas sob renovação diária da AR em relação às plantas sob renovação a cada 4 dias (Figura 2B). Os diferentes substratos de cultivo proporcionaram, nesta época de cultivo, diferenças significativas $(\mathrm{p}<0,05)$ entre os resultados de espessura da haste observados em bagaço de cana-de-açúcar em relação à fibra de coco e areia; observaram-se hastes com espessura média de $14 \mathrm{~mm}$ nas plantas cultivadas na fibra de coco, $11 \mathrm{~mm}$ nas cultivadas em areia e $2,7 \mathrm{~mm}$ nas cultivadas em bagaço de cana-de-açúcar (Figura 2C).

Aos 42 DAS notou-se uma redução de 7,7\% no DH por incremento unitário do tempo de renovação/substituição da AR; nesta época de avaliação as plantas sob AR renovada diariamente produziram hastes 1,33 vez mais espessas que as sob renovação a cada 4 dias (Figura 2B). Ovalor médio do DH para as plantas sob manejo de renovação/substituição da $\mathrm{AR}$ a cada quatro dias, foi da ordem de $9,5 \mathrm{~mm}$, valores esses inferiores aos observadas por Biscaro et al. (2008) nesta fase do crescimento da planta; apesar disto, os valores obtidos no presente experimento, independente do tratamento, estão dentro do intervalo dos limites de 5 a $15 \mathrm{~mm}$, indicados como padrão de qualidade para a flor de girassol, por Grieve \& Poss (2010).

A espessura da haste das plantas cultivadas nos diferentes subtratos testados diferiu significativamente $(\mathrm{p}<0,05)$ entre si aos 42 DAS; quando cultivadas em fibra de coco, média de 15 $\mathrm{mm}$, as hastes foram $16,47 \%$ mais espessas que a das plantas cultivadas na areia e 4,8 vezes mais espessas que o das plantas cultivadas no bagaço de cana (Figura 2C).
O manejo da AR e os diferentes substratos influenciaram significativamente o NF das plantas em todas as épocas de avaliação (Tabela 5). Aos 21 DAS observou-se que as plantas sob renovação/substituição diária da AR produziram 20,3\% mais folhas que as plantas sob renovação da $\mathrm{AR}$ a cada 4 dias, sendo notado um decréscimo de $6,3 \%$ no NF por incremento unitário do tempo de renovação (Figura 3A); quando cultivadas em fibra de coco, as plantas produziram, em média, duas folhas a mais que em areia e 6 folhas a mais que em bagaço de canade-açúcar (Figura 3C).

Aos 28 DAS o decréscimo no NF por incremento unitário do tempo de renovação/substituição da AR foi de 4,9\%; observou-se também que as plantas sob renovação diária da AR obtiveram 1,18 vez mais folhas que as plantas sob renovação/substituição da $A R$ a cada 4 dias (Figura 3A) e que, quando cultivadas em fibra de coco, produziram NF significativamente maior que o observado nas plantas cultivadas nos demais substratos testados (Figura 3C).

A redução no NF por incremento unitário do tempo de renovação da AR aos 35 DAS foi de 4,8\% (Figura 3B); em relação aos diferentes substratos testados, o efeito foi significativo e a variação média foi de 5 e 17 folhas a mais para as plantas cultivadas em fibra de coco em relação à areia e ao bagaço de cana-de-açúcar, respectivamente (Figura 3C).

Aos 42 DAS observou-se decréscimo de 4,6\% por incremento unitário do tempo de renovação da AR no NF (Figura 3B). Em relação aos diferentes substratos, verificou-se efeito significativo $(\mathrm{p}<0,05)$ e uma diferença média de 9 e 20 folhas a mais nas plantas cultivadas em fibra de coco quando comparado com o NF das plantas cultivadas em areia e bagaço de cana-de-açúcar, respectivamente (Figura 3C). De acordo com Maciel et al. (2012), o principal objetivo do cultivo do girassol ornamental é a venda de sua haste floral como flor de corte de modo que os principais arranjos e buquês descartam as folhas por ocasião da colheita da flor; entretanto, durante a fase de crescimento das plantas o número e a qualidade das folhas influenciam diretamente aspectos fisiológicos importantes, como a fotossíntese.

Todos os tratamentos testados ocasionaram efeito significativo na AF das plantas de girassol em todas as épocas de avaliação (Tabela 6).

Aos 21 DAS observou-se que o manejo da AR provocou decréscimo linear de $10,3 \%$ na área foliar por incremento unitário do tempo de renovação/substituição da AR (Figura $4 \mathrm{~A})$; quanto aos diferentes substratos testados, notou-se que

Tabela 5. Resumo da ANOVA para o número de folhas ${ }^{1}$ de plantas de girassol (cv. Embrapa 122-V2000) aos 21, 28, 35 e 42 dias após a semeadura (DAS) cultivadas em diferentes substratos e tempos de renovação/substituição da água residuária

\begin{tabular}{|c|c|c|c|c|c|}
\hline \multirow{2}{*}{ Causa de variação } & \multirow{2}{*}{ GL } & \multicolumn{4}{|c|}{ Quadrado médio } \\
\hline & & 21 DAS & 28 DAS & 35 DAS & 42 DAS \\
\hline Tempo de renovação da AR (T) & 3 & $4,9629^{* *}$ & $5,9629^{*}$ & $13,0740^{*}$ & $12,5462^{*}$ \\
\hline Regressão linear & 1 & $11,7555^{\star *}$ & $17,4222^{\star \star}$ & $21,3555^{\star}$ & $34,6722^{*}$ \\
\hline Substrato (S) & 2 & $132,027^{\star \star}$ & $440,4444^{\star *}$ & $1005,861^{\star *}$ & $1342,361^{\star *}$ \\
\hline Interação T x S & 6 & $2,1018^{\text {ns }}$ & $0,8518^{\text {ns }}$ & $2,1574^{\mathrm{ns}}$ & $5,3240^{\text {ns }}$ \\
\hline Resíduo & 24 & 1,2777 & 1,0833 & 3,3611 & 4,5277 \\
\hline CV & $(\%)$ & 8,99 & 4,44 & 5,90 & 6,17 \\
\hline
\end{tabular}

\footnotetext{
*, ** Significativo a 0,05 e 0,01 de probabilidade, respectivamente; ns - Não significativo, pelo teste F; GL - Grau de liberdade; CV- Coeficiente de variação.
}

${ }^{1}$ Valores transformados pela equação $(X+0,5)^{0,5}$ 
A.

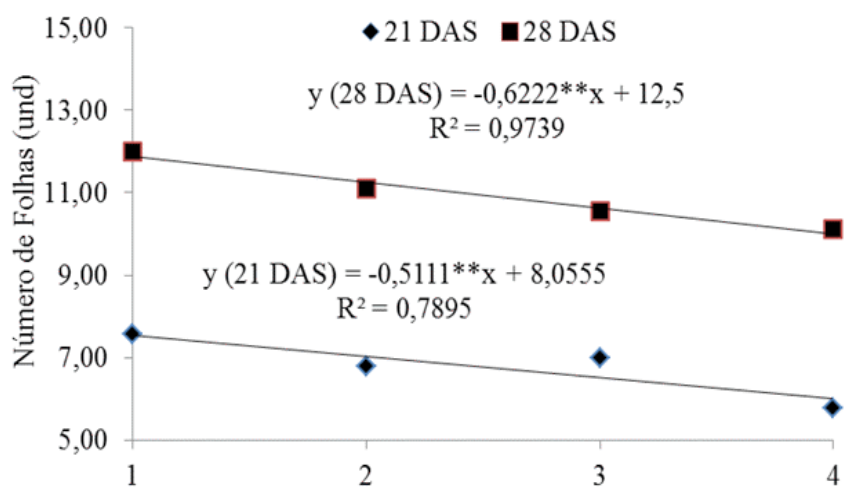

B.

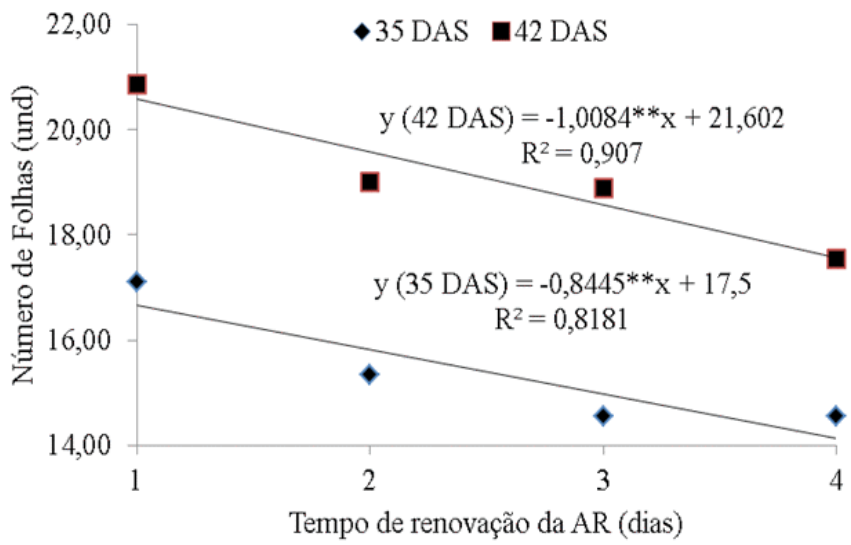

C.

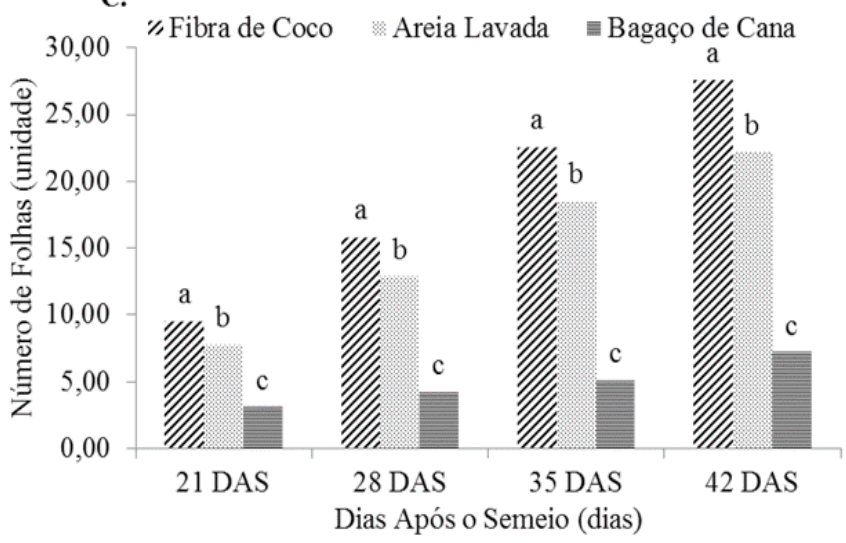

Figura 3. Número de folhas aos 21, 28 (A), 35 e 42 dias após a semeadura (DAS) de plantas de girassol (cv. Embrapa 122-V2000) (B) em função do diferentes tempos de renovação/substituição da água residuária e em função dos diferentes substratos (C) as plantas cultivadas em fibra de coco apresentaram AF média cerca de 1,61 vez maior que as plantas cultivadas na areia e 22 vezes maior em relação às plantas cultivadas em bagaço de cana-de-açúcar (Figura 4C).

$\mathrm{Na}$ análise do desdobramento da interação entre os fatores, ainda aos 21 DAS, observou-se significância do fator substrato dentro do fator renovação/substituição da AR. As plantas cultivadas em fibra de coco sob AR renovada a cada 2 dias, apresentaram área foliar em média de $603,3 \mathrm{~cm}^{2}$, ou seja, um acréscimo de $24 \%$ em relação à área foliar das plantas sob renovação diária e a cada 3 dias, no mesmo substrato; as plantas cultivadas em areia apresentaram área foliar em média de 300 $\mathrm{cm}^{2} \mathrm{e}$ as cultivadas em bagaço de cana-de-açúcar, média de 21 $\mathrm{cm}^{2}$, para renovação da AR a cada 3 dias da (Figura 4D).

Aos 28 DAS notou-se decréscimo linear da AF por incremento unitário do tempo de renovação/substituição da AR na ordem de 10,1\% (Figura 4A); observou-se, também, que quando a renovação da AR é diária a área foliar das plantas é até 33,7\% maior em relação às plantas sob $\mathrm{AR}$ renovada a cada 4 dias. A área foliar das plantas cultivadas nos diferentes substratos testados diferiu significativamente entre si; em fibra de coco observaram-se médias de $1.317 \mathrm{~cm}^{2}$, valor $40 \%$ maior que em areia e 36,68 vezes maior que em bagaço de cana-deaçúcar (Figura 4C).

Aos 35 DAS observou-se um incremento de até $60 \%$ quando se compara a área foliar das plantas sob renovação diária da AR e a cada 4 dias; verificou-se também que com o incremento unitário do tempo de renovação/substituição da AR, a área foliar das plantas decresceu linearmente na ordem de 13,7\% (Figura 4B). Quanto ao fator substrato, notou-se que as plantas cultivadas em fibra de coco apresentaram área foliar em média de 2.826 $\mathrm{cm}^{2}$; as plantas cultivadas em areia de $1.726 \mathrm{~cm}^{2}$ e em bagaço de cana-de-açúcar de $35 \mathrm{~cm}^{2}$, ou seja, uma diferença de até $38,9 \%$ quando se comparam os resultados observados em fibra de coco em relação à areia (Figura 4C). No desdobramento da interação entre os fatores observou-se, aos 35 DAS, significância para o fator substrato dentro do fator renovação da AR, sendo factível ressaltar que sob renovação diária da $\mathrm{AR}$ as plantas cultivadas em fibra de coco apresentaram uma área foliar 30\% maior em relação ao verificado em plantas cultivadas em areia; quando a renovação da AR é a cada 2 dias esta diferença sobe para 47\% (Figura 4E).

Aos 42 DAS observou-se decaimento de $16,6 \%$ na área foliar das plantas por incremento unitário do tempo de renovação/ substituição da AR (Figura 4B). Nobre et al. (2011) verificaram, estudando o crescimento do girassol (cv. Embrapa 122-V2000)

Tabela 6. Resumo da ANOVA para a área foliar ${ }^{1}$ de plantas de girassol (cv. Embrapa 122-V2000) aos 21, 28, 35 e 42 DAS, cultivadas em diferentes substratos e tempos de renovação/substituição da água residuária

\begin{tabular}{|c|c|c|c|c|c|}
\hline \multirow{2}{*}{ Causa de variação } & \multirow{2}{*}{ GL } & \multicolumn{4}{|c|}{ Quadrado médio } \\
\hline & & 21 DAS & 28 DAS & 35 DAS & 42 DAS \\
\hline Tempo de renovação da $A R(T)$ & 3 & $26940,56^{\star \star}$ & $161586,95^{\star \star}$ & $1860070,9^{* \star}$ & $8487865,5^{\star *}$ \\
\hline Regressão linear & 1 & $53043,97^{\star \star}$ & $415662,29^{* *}$ & $4577949,9^{* *}$ & $23401505,01^{\star \star}$ \\
\hline Substrato (S) & 2 & $545040,21^{\star *}$ & $4966361,68^{* \star}$ & $23725865,9^{* \star}$ & $62978406,7^{\star *}$ \\
\hline Interação T x S & 6 & $19290,21^{* *}$ & $45193,955^{\text {ns }}$ & $516208,130^{* *}$ & $2289627,8^{* *}$ \\
\hline Resíduo & 24 & 4958,83 & 18384,441 & 64472,265 & 224396,106 \\
\hline CV & $(\%)$ & 19,07 & 9,01 & 8,36 & 9,09 \\
\hline
\end{tabular}

* ,**Significativo a 0,05 e 0,01 de probabilidade, respectivamente; ns - Não significativo, pelo teste F; GL - Grau de liberdade; CV- Coeficiente de variação.

${ }^{1}$ Valores transformados pela equação $(X+0,5)^{0,5}$ 

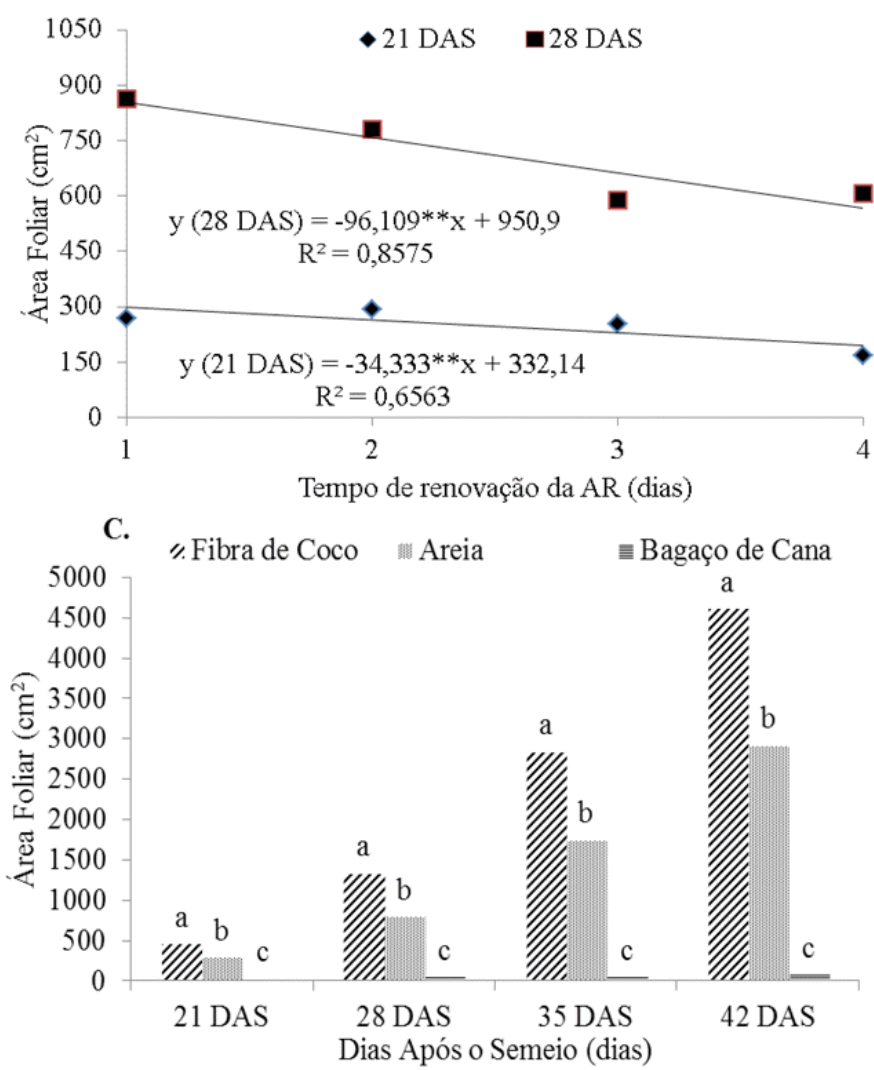

E.

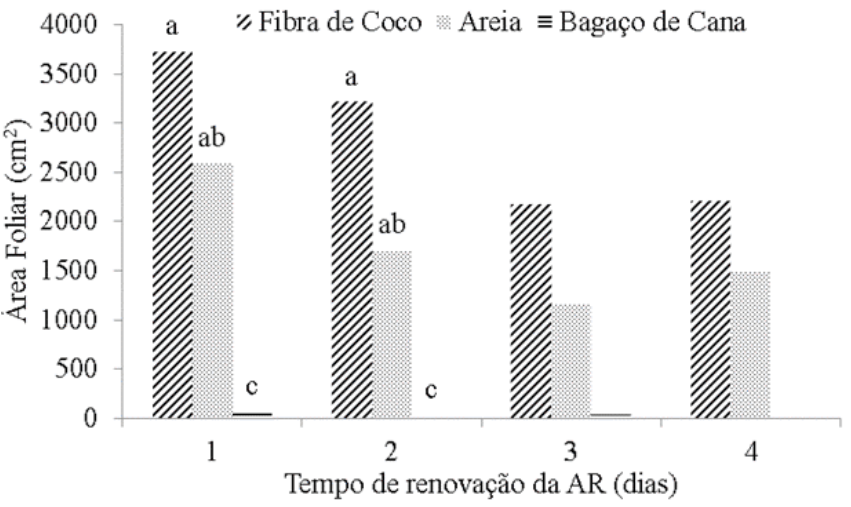

B.

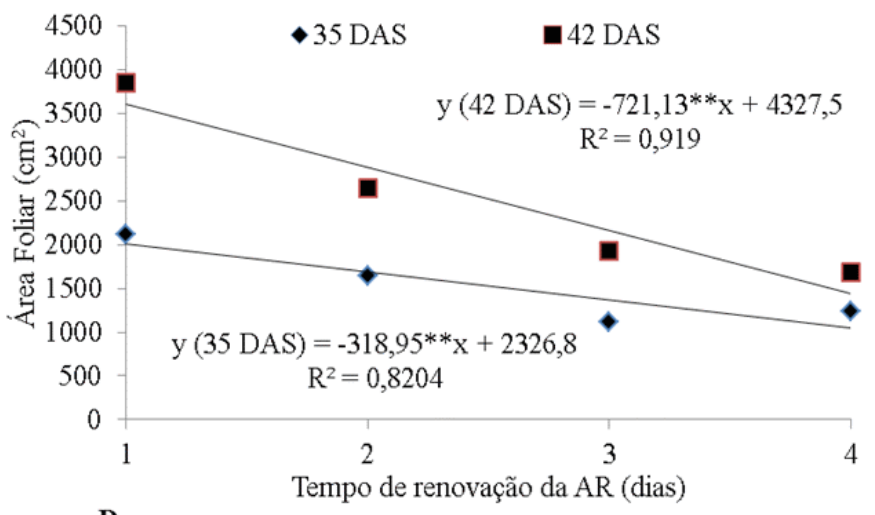

D.
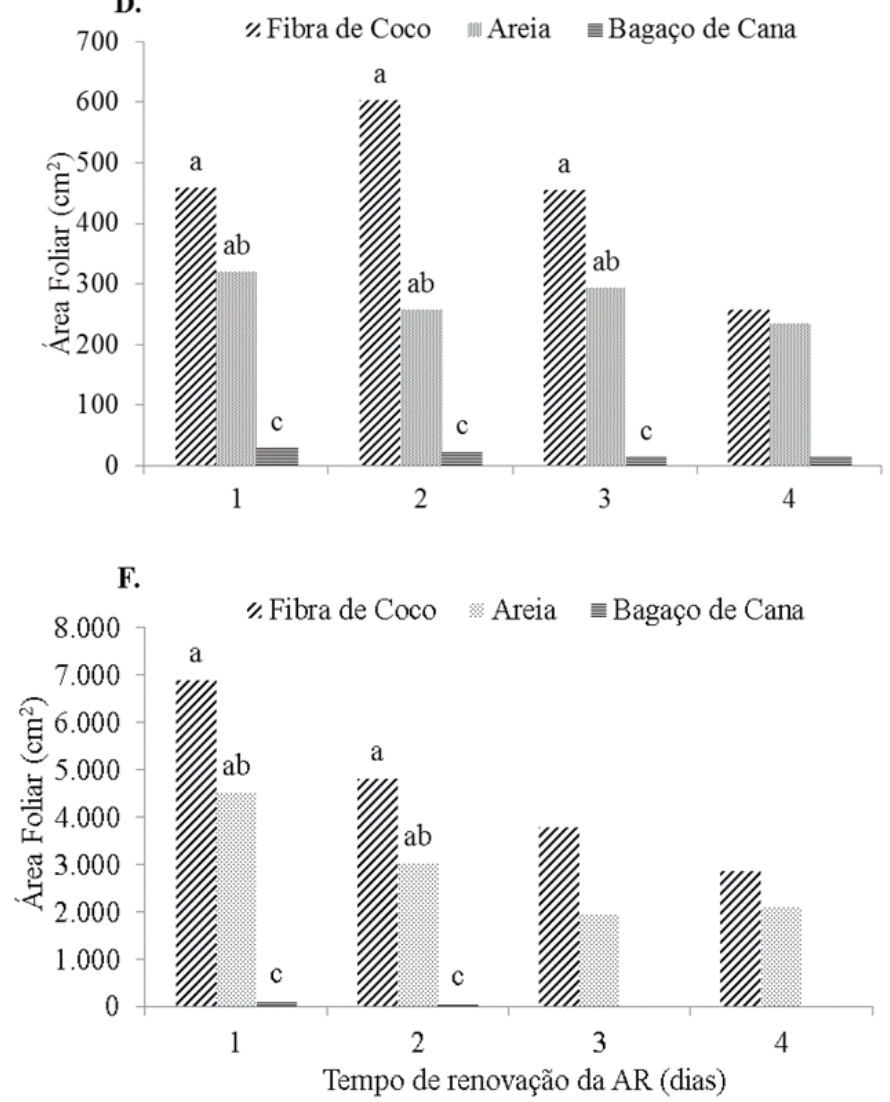

Figura 4. Área foliar aos 21, 28 (A), 35 e aos 42 dias após o semeio (DAS) (B) de plantas de girassol (cv. Embrapa 122-V2000) em diferentes tempos de renovação/substituição da água residuária e substratos (C). Desdobramento do fator substrato dentro do fator tempo de renovação/substituição da água residuária aos 21 (D), 35 (E) e 42 DAS (F)

sob estresse salino e adubação nitrogenada, aos 50 DAS, para as plantas irrigadas com água de $0,5 \mathrm{dS} \mathrm{m}^{-1}$, índices de área foliar da ordem de $2600 \mathrm{~cm}^{2}$, ou seja, valores inferiores aos encontrados no presente trabalho para as plantas sob renovação/ substituição diária da AR; entretanto, $34,6 \%$ superiores aos das plantas sob renovação da AR a cada quatro dias $\left(1700 \mathrm{~cm}^{2}\right)$ nesta mesma época de avaliação. Em relação aos diferentes substratos, observou-se que as plantas cultivadas em fibra de coco obtiveram área foliar (média de $4.601 \mathrm{~cm}^{2}$ ) cerca de 36,86\% maiores em relação às plantas cultivadas em areia e 68,36 vezes maior quando se compara com a $\mathrm{AF}$ das plantas cultivadas em bagaço de cana-de-açúcar (Figura 4C).

A interação entre os fatores também ocasionou efeito significativo na AF das plantas aos 42 DAS. No desdobramento do fator substrato dentro do fator renovação da AR, observou-se que as plantas cultivadas em fibra de coco sob renovação diária da AR produziram área foliar média de $6.902 \mathrm{~cm}^{2}$; nesta mesma data as plantas sob renovação a cada 2 dias e cultivadas em fibra de coco produziram uma área foliar em média de $4.821 \mathrm{~cm}^{2}$ (Figura $4 \mathrm{~F}$ ). Em relação às plantas cultivadas na areia, a diferença foi de até $34,5 \%$ quando comparada com a área foliar das plantas cultivadas em fibra de coco sob renovação diária da AR.

\section{Conclusões}

1. O tempo de renovação afetou negativamente o comprimento e o diâmetro da haste e do número de folhas e área foliar; no entanto, esses parâmetros de crescimento das 
flores se mantiveram dentro dos padrões comerciais, em todos os tempos testados.

2. A fibra de coco apresentou-se como a melhor opção de substrato, seguida da areia, não sendo recomendado o uso do bagaço de cana-de-açúcar para o cultivo de girassol (cv. Embrapa 122-V2000) em sistema semi-hidropônico.

3. As plantas sob renovação da água residuária a cada dois dias apresentaram maiores valores de comprimento do caule, diâmetro do caule, número de folhas e área foliar até os 28 dias após o semeio; a partir desta data, os melhores resultados foram verificados nas plantas sob renovação diária, desde que seja utilizada fibra de coco ou areia como substrato.

4. É viável utilizar o potencial hídrico e nutricional da água residuária na produção comercial de flores de girassol em sistema semi-hidropônico com renovação/substituição do percolado, em até quatro dias.

\section{Literatura Citada}

Alves, W. W. A.; Dantas Neto, J.; Lima, V. L. A. de. Área foliar do algodoeiro irrigado com água residuária adubado com nitrogênio e fósforo. Revista Verde de Agroecologia e Desenvolvimento Sustentável, v.4, p.41-46, 2009.

Andrade, L. O. de; Gheyi, H. R.; Nobre, R. G.; Dias, N. da S.; Nascimento, E. C. S. Qualidade de flores de girassóis ornamentais irrigados com águas residuária e de abastecimento. Idesia, v.30, p.19-27, 2012.

Biscaro G. A.; Machado, J. R.; Tosta, M. da S.; Mendonça, V.; Soratto, R. P.; Carvalho, L. A. de. Adubação nitrogenada em cobertura no girassol irrigado nas condições de CassilândiaMS, Revista Ciência e Agrotecnologia, v.32, p.1366-1373, 2008.

Chatzakis, M. K.; Tzanakakis, V. A.; Mara, D. D.; Angelakis, A. N. Irrigation of castor bean (Ricinus communis L.) and sunflower (Helianthus annus L.) plant species with municipal wastewater effluent: Impacts on soil properties and seed yield. Water, v.3, p.1112-1127, 2011.

Curti, G. L. Caracterização de cultivares de girassol ornamental semeados em diferentes épocas no Oeste Catarinense. Pato Branco: UFPR, 2010. 76p. Dissertação Mestrado
EMBRAPA - Empresa Brasileira de Pesquisa Agropecuária. Centro Nacional de Pesquisa de Solos. Manual de métodos de análise de solo. 2.ed. Rio de Janeiro: EMBRAPA, 1997. 212p.

Ferreira, D. F. Sisvar: Um programa para análises e ensino de estatística. Revista Symposium, v.6, p.36-41, 2008.

Grieve, C. M.; Poss, J. A. Response of ornamental sunflower cultivars 'Sunbeam' and 'Moonbright' to irrigation with saline wastewaters. Journal of Plant Nutrition, v.33, p.15791592, 2010.

Maciel, P. M.; Soares, T. M.; Gheyi. H. R.; Rezende, E. P. L.; Oliveira, G. X. S. Produção de girassol ornamental com uso de águas salobras em sistema hidropônico NFT. Revista Brasileira de Engenharia Agrícola e Ambiental, v.16, p.162165, 2012.

Maldaner, I. C.; Heldwein, A. B.; Loose, L.H.; Lucas, D. D. P.; Guse, F. I.; Bortoluzzi, M.P. Métodos de determinação nãodestrutiva da área foliar em girassol, Ciência Rural, v.39, p.1356-1361, 2009.

Medeiros, S. S.; Cavalcante, A. de M. B.; Perez Marin, A. M.; Tinoco, L. B. de M.; Salcedo, I. H.; Pinto, T. F. Sinopse do censo demográfico para o semiárido brasileiro. Campina Grande: INSA, 2012. 103p.

Neves, M. B.; Andréo, Y. de S.; Watanabe, A. A.; Fazio, J. L. de; Boaro, C. S. F. Uso de daminozide na produção de girassol ornamental cultivados em vaso. Revista Eletrônica de Agronomia, v.16, p.31-37, 2009.

Neves, M. F.; Amaral, R. O. Flores - oportunidades e desafios. Revista Agro Analysis, v.27, p.30-31, 2008.

Nobre, R. G.; Gheyi, H. R.; Soares, F. A. L.; Cardoso, J. A. F. Produção de girassol sob estresse salino e adubação nitrogenada. Revista Brasileira de Ciência do Solo, v.35, p.929-937, 2011.

Rebouças, J. R. L.; Dias, N. S.; Gonzaga, M. I. S.; Gheyi, H.R.; Sousa Neto, O. N. Crescimento do feijão-caupi irrigado com água residuária de esgoto doméstico tratado. Revista Caatinga, v.23, p.97-102, 2010.

Santos Júnior, J. A.; Gheyi, H. R.; Dias, N. da S.; Soares, F. A. L.; Nobre, R. G. Doses de boro e água residuária na produção de girassol. Revista Ciência Agronômica, v.42, p.857-864, 2011. 